\title{
OBSEDUUID
}

Mario Muñoz

Pensaba que para ella esa amistad no tenía ningún interés o que de plano lo detestaba. Pero la verdad es que la citaba para observar su cabello oscuro hecho nudo detrás de la nuca, los ojos negros circundados por la intensa línea de las cejas, la nariz recta que armonizaba con el fino trazo de los labios, los complicados tatuajes...

\section{Para Evaluna}

ormía con una calma aparente cuando despertó aterrorizado. Era la quinta o sexta vez que soñaba la misma pesadilla, sin encontrar alguna explicación a la imagen que durante el día empezaba a inquietarlo. Bastante alterado para poder conciliar el sueño, pasó el resto de la noche dando vueltas en la cama con el corazón palpitándole. Solo hasta que la claridad empezó a filtrarse entre las cortinas pudo descansar un poco. Cuando se levantó, volvió a perturbarlo el recuerdo de la pesadilla, tanto que casi había olvidado ver a su amiga por la tarde donde solían encontrarse.

A las seis salió del departamento con rumbo al café. Les agradaba el lugar porque era un caserón de altos techos adaptado para el negocio. El decorado recreaba una estética dark que acentuaba la música envolvente de Enigma, Black Sabbath, Pink Floyd, sabiamente dispuesta para no interferir en la conversación de los clientes asiduos, escasos por cierto. La tenue iluminación realzaba la penumbra dando al ambiente un premeditado toque efectista.

Al llegar encontró a la joven en su lugar habitual. Vestía una blusa negra y leggings del mismo color. Bebía un exprés mientras leía un libro que dejó sobre la mesa cuando él estuvo frente a ella. Se saludaron de mano con la formalidad de costumbre. Tenían meses de conocerse pero mantenían la misma distancia en el trato. La camarera se acercó a tomar la orden. Pidió un café doble con crema. Luego de intercambiar algunas palabras permanecieron en silencio. No era de conversación fácil por más que él intentara animar la plática. Pensaba que para ella esa amistad no tenía ningún interés o que de plano lo detestaba. Pero la verdad es que la citaba para observar su cabello oscuro hecho nudo detrás de la nuca, los ojos negros circundados por la intensa línea de las cejas, la nariz recta que armonizaba con el fino trazo de los

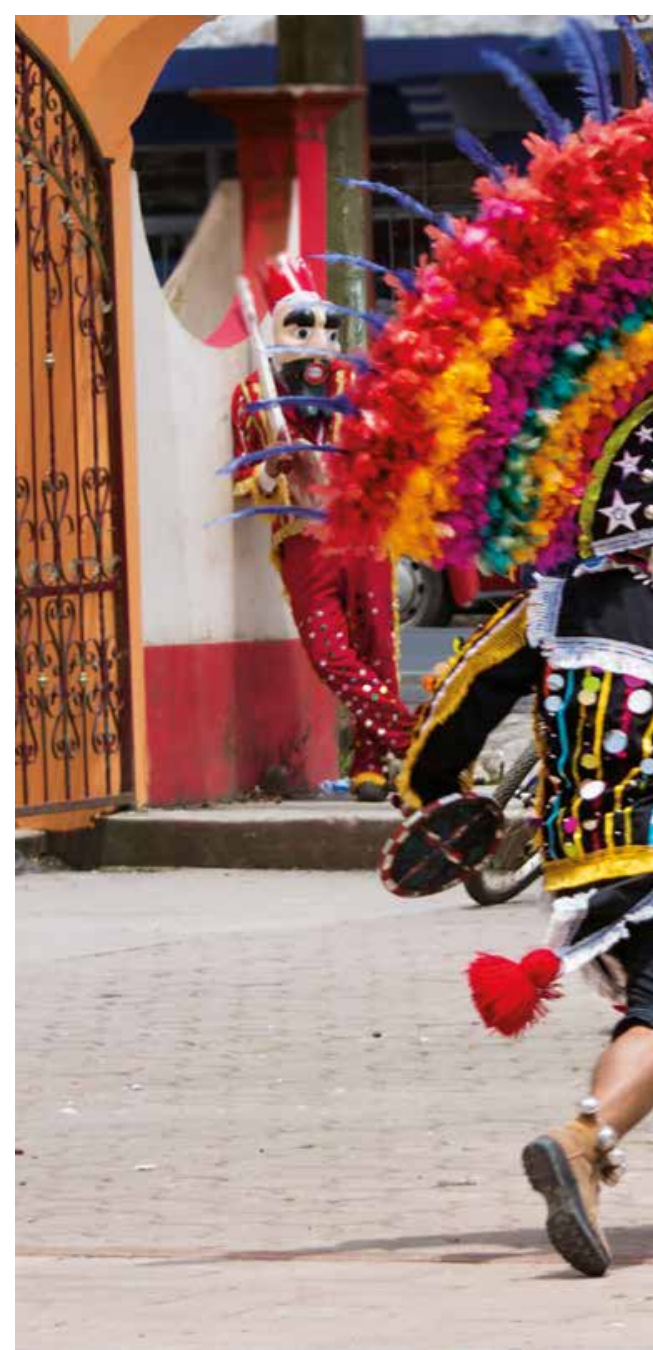

labios, los complicados tatuajes de los brazos que acentuaban el matiz marfileño de las manos de largas uñas nacaradas. Le bastaba observarla a detalle para llenar sus días hasta el siguiente encuentro en el que nada cambiaría: una rueda girando en el mismo eje cuyas vueltas cesarían la vez que, fastidiada, no volviera más.

La camarera le trajo el pedido. Vació la crema en el café y paladeó el primer trago. Trató de iniciar de algún modo la plática, preguntándole qué estaba leyendo. Le mostró la portada del libro. No, no lo conocía. Después permanecieron callados largo rato. Distraída, apática, indiferente, recorría con 


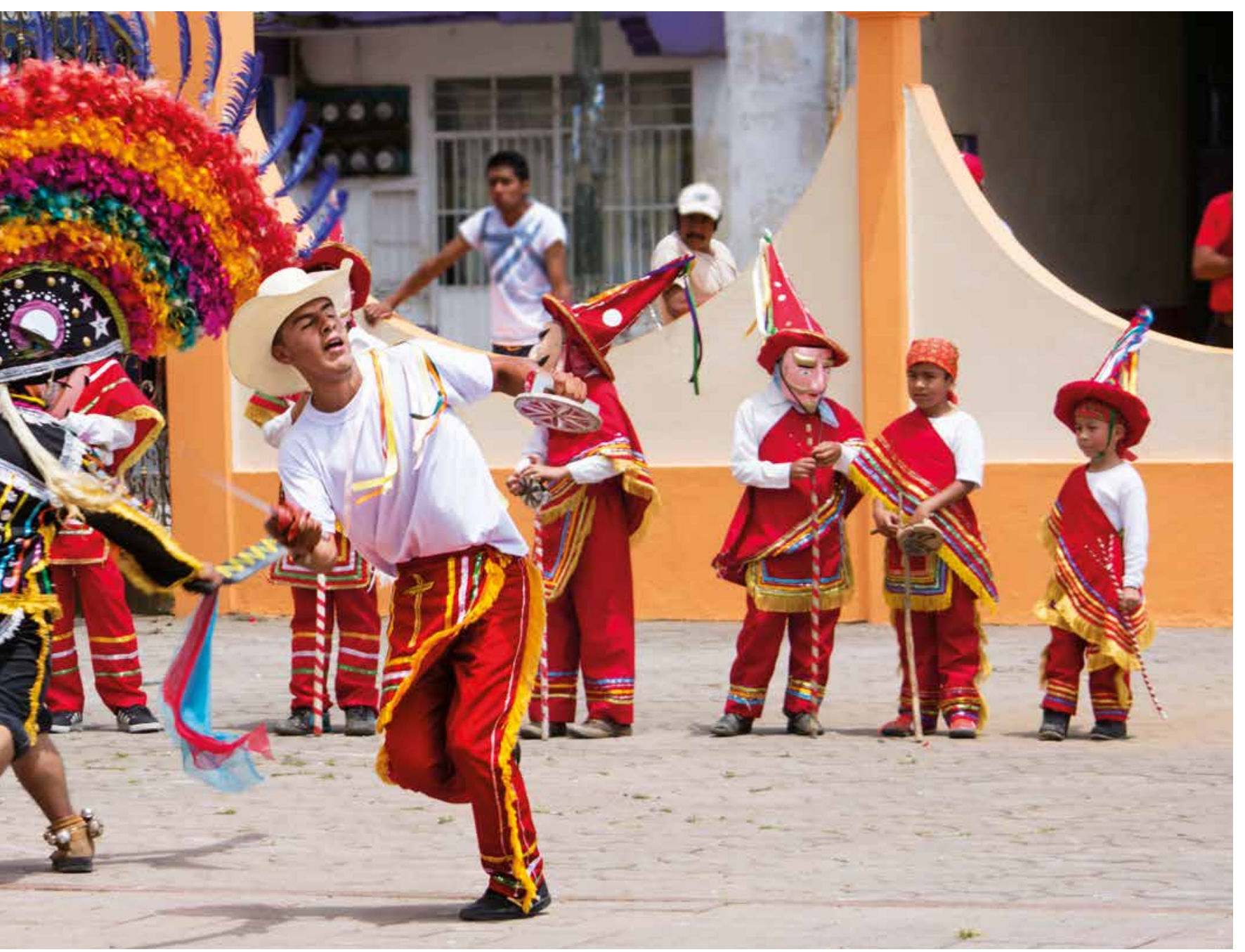

la mirada el local vacío. Al fondo, la camarera dormitaba acodada en el mostrador. Ningún ruido provenía del exterior; solo el sonido ambiental deslizaba muy tenue "Smell of desire"...

Por algún motivo empezó a inquietarse. Sintió un ligero mareo. Era como si un coágulo comenzara a formarse en algún recóndito lugar del cerebro. Volvieron las palpitaciones nocturnas, la sensación de ahogo, la turbulencia de las entrañas. Lentamente el coágulo empezó a precisar sus contornos, a delinear los rasgos de cierta figura. La conciencia pugnaba por emerger del magma que la tenía atrapada hasta que la vaguedad de esa forma empezó a materializarse en la realidad concreta que tenía frente a él. Lo que estaba viendo era lo que había dado origen a los espantosos sueños recurrentes en las noches interminables.

Entonces, creyó oír:

-Te voy a regalar mi cabeza para que siempre la admires.

Asustado, observó los movimientos habituales en ella de abrir y cerrar la boca varias veces como si destrabara las mandíbulas; luego, ella jaló el costado derecho de su cabeza con la mano izquierda presionando el mentón hacia arriba con la derecha como intentando girarla a modo de torniquete sin dejar de mirarlo.
Maquinalmente extendió los brazos, tomó la cabeza chorreante pero al momento la dejó caer horrorizado sobre la mesa. Oyó un golpe seco, dio un grito, se levantó de un impulso derramando los restos fríos del café y huyó despavorido. Ella lo siguió con la mirada, cogió el libro y continuó la lectura.

Afuera, la noche era un latigazo en la espalda de la realidad. LPyH

Mario Muñoz es profesor de tiempo completo en la Facultad de Letras Españolas de la Uv. Recientemente compiló la antología Doce relatos hispanoamericanos imprescindibles del siglo $\mathrm{xx}$ en la colección Biblioteca del Universitario de la Uv. 